\title{
Experimental Investigation and Optimization Design of Multi-Support Pipeline System
}

\author{
Xiantao Zhang, Wei Liu*, Yamei Zhang and Yujie Zhao
}

\begin{abstract}
The design of aircraft hydraulic pipeline system is limited by many factors, such as the integrity of aviation structure or narrow installation space, so the limited clamp support position should be considered. This paper studied the frequency adjustment and dynamic responses reduction of the multi-support pipeline system through experiment and numerical simulation. To avoid the resonance of pipeline system, we proposed two different optimization programs, one was to avoid aero-engine working range, and another was to avoid aircraft hydraulic pump pulsation range. An optimization method was introduced in this paper to obtain the optimal clamp position. The experiments were introduced to validate the optimization results, and the theoretical optimization results can agree well with the test. With regard to avoiding the aero-engine vibration frequency, the test results revealed that the first natural frequency was far from the aero-engine vibration frequency. And the dynamic frequency sweep results showed that no resonance occurred on the pipeline in the engine vibration frequency range after optimization. Additionally, with regard to avoiding the pump vibration frequency, the test results revealed that natural frequencies have been adjusted and far from the pump vibration frequency. And the dynamic frequency sweep results showed that pipeline under optimal clamp position cannot lead to resonance. The sensitivity analysis results revealed the changing relationships between different clamp position and natural frequency. This study can provide helpful guidance on the analysis and design of practical aircraft pipeline.
\end{abstract}

Keywords: Multi-support pipeline system, Clamp position optimization, Frequency adjustment design, Dynamic responses

\section{Introduction}

The function of hydraulic system is to maintain the running of aircraft. During the aircraft operation, external excitation inevitably stimulates the vibration of the hydraulic pipeline system, which leads to pipeline fracturing and fatigue failure $[1,2]$. It is accepted that layout and arrangement of pipeline directly influence pipeline's dynamic characteristics under vibration environment. However, the design of pipeline system is restricted by many factors such as limited installation space. Additionally, the bending layout design may lead to clamps hardly install on the optimized positions. Therefore, the limited support position and pipeline responses under excitation

\footnotetext{
*Correspondence: liuwei@nwpu.edu.cn

School of Mechanics, Civil Engineering and Architecture, Northwestern Polytechnical University, Xi'an 710129, China
}

must be considered in the design of aviation hydraulic pipelines.

Abundant achievements have been made in the study of nonlinear dynamics and anti-vibration design of hydraulic pipelines. Bezborodov et al. [3] considered the relationship between the complexity of pipe shape and pipe vibration, and the damping of joint support, then they established a mathematical model to solve the vibration and stress responses of pipeline. Mamaghani et al. [4] studied the effect of nonlinear energy sink on the vibration reduction of the pipeline under excitation. They found that installing nonlinear energy sink in the middle of pipeline can achieve the best vibration absorption effect. Chai et al. [5] studied the nonlinear dynamic characteristics of L-type pipeline system with clamps, and verified the correctness of bilinear stiffness and damping model by finite element simulation and experiment. 
Gao et al. [6-8]studied the damping vibration reduction method of aircraft hydraulic pipeline, and verified the vibration reduction effect through experiments.

Because of the importance of hydraulic pipeline system, we need to consider many design factors at the same time. For example, design factors like reliability, narrow space, the cost of design, and so on [3]. To improve quality and efficiency of the pipeline layout, various studies have proposed automatic layout optimization algorithms for pipelines, such as a fast and elitist non-dominated sorting genetic algorithm (GA) [9-11], particle swarm optimization [12], Maze algorithm [13], Multi-objective particle swarm optimization [14], pipeline layout method based on intelligent optimization [15, 16], and so on. These intelligent algorithms provided new solutions to the optimization design of aviation pipelines. Compared with the design of other vehicle pipelines, there are some matters that designers should mainly focus [17]: (1) the pipeline installation mainly depends on standards and experience; (2) narrow installation space; (3) withstanding multiple excitation sources; (4) weakening of elastic support. These problems pose new challenges to pipeline design.

In recent years, various breakthroughs have been achieved in the optimal design of pipeline. Using the particle swarm optimization algorithm and the characteristic impedance of the system, Li et al. [18] minimized the weighted sum of the characteristic impedance by optimizing the clamp position, and thus successfully reduced the vibration of the liquid-filled pipeline. $\mathrm{Li}$ et al. [19] introduced structure optimization into turbo-charged pipe design and proposed the developed pipe structure can successfully meet the aim of both noise reduction and pressure drop.

Liu et al. [20] analyzed the dynamic sensitivity of the clamp position in an aero-engine pipeline and proposed an optimal design scheme for two sets of clamps with the objective of maximizing the fundamental frequency difference and minimizing the standard deviation of random vibration. Jiang et al. [21] proposed a branch pipeline laying method based on the ant colony algorithm, which dealt with the problem as a multi-branch pipe route design problem, and applied cooperative thinking to solve the problem. Qu et al. [22] presented a new three-dimensional connection graph. He selected the length of the pipelines and the number of bends as the optimal design objective. In his following work, the ant colony algorithm was introduced to investigate the pipeline layout design of the aero-engine. Owing to the complicated design process and various design parameters, a comprehensive optimization procedure must be considered in the design. This can be achieved by applying a rigorous optimization technique.
This paper proposed an optimization method for the natural frequency adjustment and dynamic response reduction of the multi-support pipeline system. Additionally, by conducting a series of experiments, it is confirmed that the optimization effect satisfies the engineering requirement. It should be clearly noted that Ref. [23] showed the fluid velocity variation had little influence on the pipeline's natural frequency and vibration mode. The internal fluid pressure also had little influence on pipeline's mode because of the large stiffness of stainless-steel pipeline, the effect of fluid is not considered. In this paper, the adjustment of natural frequencies and the reduction of dynamic responses are set as the two optimization objectives. Then a GA method is used to calculate the optimal clamp position which can achieve the purpose that frequency adjustment and dynamic responses minimization. Moreover, the sensitivity analysis is carried out to determine the relationship between the moving distance of the supports and the natural frequencies. Particularly, to verify the effect of the theoretical optimization effects, this paper proposes a test device for simulating the multi-support pipeline system and verifying the optimization scheme.

\section{Modeling and Parameterization of Multi-Support Pipeline System}

\subsection{Geometric Model}

Figure 1 shows the multi-support aircraft hydraulic pipeline system, which includes four parts: supporting platform, pipeline, clamps, rib beams. The horizontal length of the pipeline was $\mathrm{L}=1650 \mathrm{~mm}$ and the vertical length was $\mathrm{H}=200 \mathrm{~mm}$. The external pipeline diameter was $\mathrm{D}=8 \mathrm{~mm}$, and the thickness was $\delta=0.8 \mathrm{~mm}$. The pipeline was fixed onto six rib beams using clamps. The height of the support platform was $\mathrm{h}=500 \mathrm{~mm}$, and the rib beams were fixed onto the supporting platform through bolts.

\subsection{Model Simplification and Parameterization}

Before the finite element (FE) modeling, the multi-support pipeline system was simplified as follows.

(1) The multi rib-beam supports were simplified. In this paper, the rib beam supports could be omitted, and the support position was expressed by changing the clamp position.

(2) The constraint relationship of the simplified model was consistent with the test; that is, the lateral and axial displacement of the pipeline were restrained, while the clamps were fixed.

(3) The contact between clamp and pipe cannot be considered as full constraint. Thus, the contact was set as frictional and the friction coefficient was 0.25 . Additionally, the terminal of pipeline was con- 


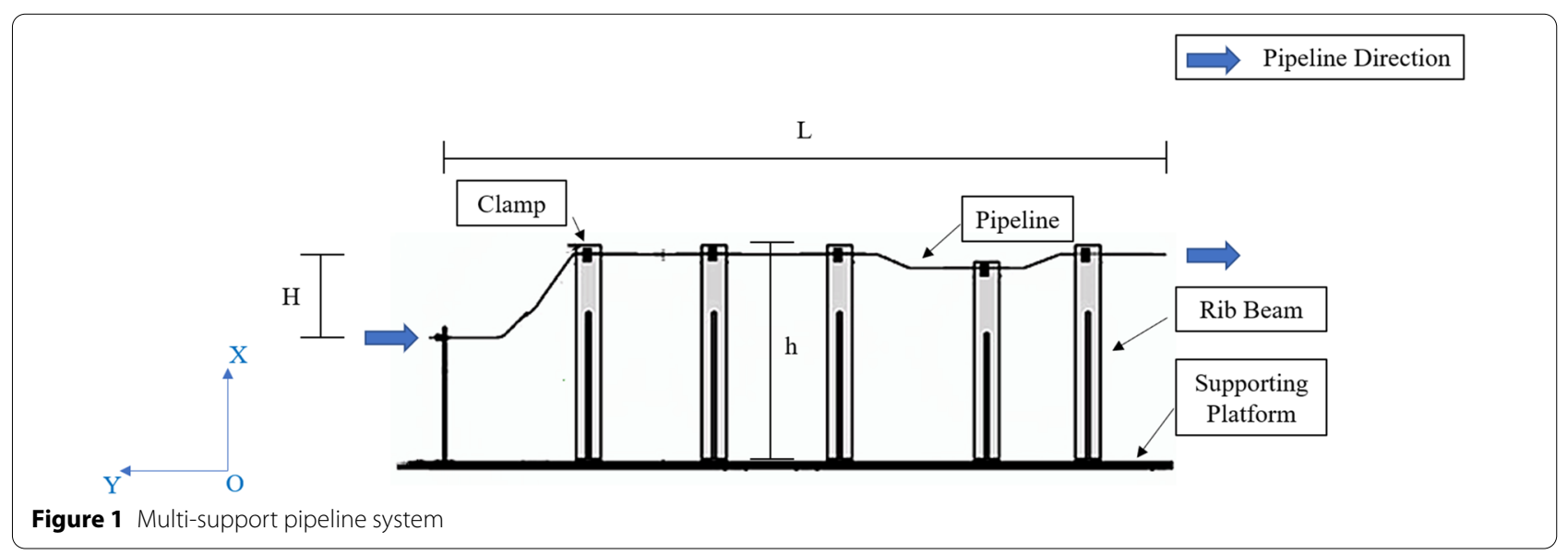

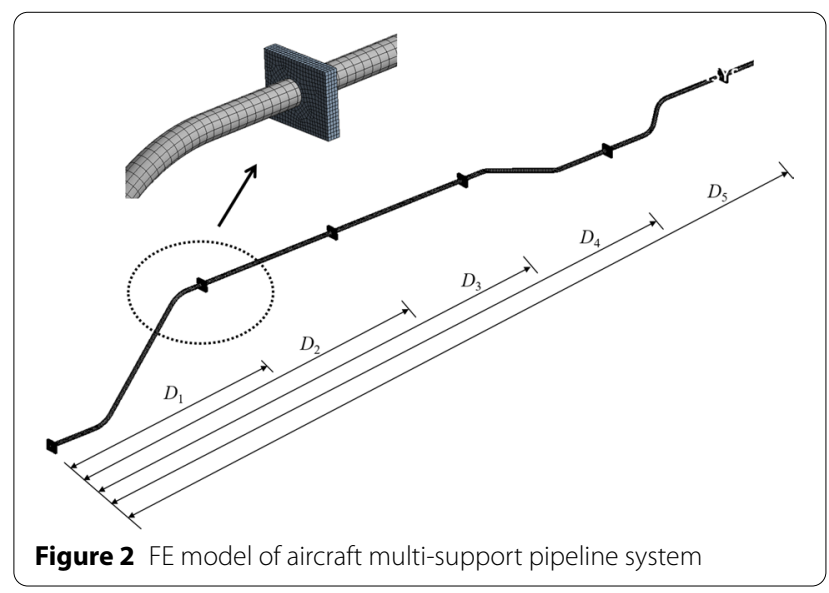

nected by pipe joint; thus, this part of the connection boundary was different from others and could be set as a full constraint.

To distinguish different clamps, capital letters from A to $\mathrm{F}$ were used to define them. Owing to the narrow space of the airframe, reasonable clamp positions are important for hydraulic pipeline system and help avoid vibration faults. We defined $D_{i}$, where $i=1,2, \ldots, 5$, as the clamp positions. For example, $D_{1}$ was the distance between clamp $\mathrm{A}$ and $\mathrm{B} ; D_{2}$ was the distance between clamp A and C; $D_{3}$ was the distance between clamp A and $\mathrm{D} ; D_{4}$ was the distance between clamp A and E; $D_{5}$ was the distance between clamp A and F. The schematic diagram is shown in Figure 2 and the original parameters are listed in Table 1.

The pipeline material was $0 \mathrm{Cr} 18 \mathrm{Ni} 9$ stainless steel; the rib beam supports and the supporting platform
Table 1 Original parameters of clamp locations ( $\mathrm{mm}$ )

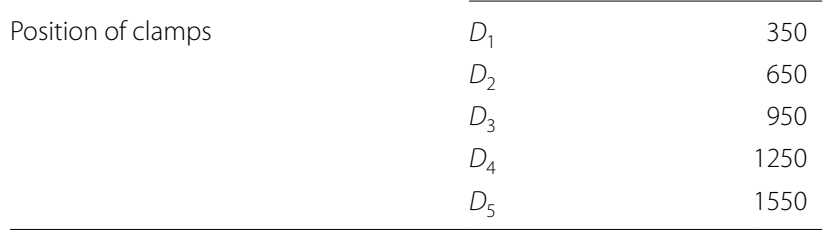

Table 2 Structural material parameters

\begin{tabular}{lcll}
\hline & $\begin{array}{l}\text { Elasticity } \\
\text { modulus (GPa) }\end{array}$ & $\begin{array}{l}\text { Density } \mathbf{( k g /} \\
\mathbf{c m}^{\mathbf{3}} \text { ) }\end{array}$ & Poisson's ratio \\
\hline Pipeline & 210 & 7.85 & 0.33 \\
Clamps & 75 & 2.8 & 0.25 \\
Rib beams & 210 & 7.85 & 0.33 \\
\hline
\end{tabular}

were made of steel; the clamps were made of aluminum. The material details are listed in Table 2.

\section{Numerical Simulation of Multi-Support Pipeline System}

The FE model of the multi-support aircraft pipeline system was established in the previous part. The external excitation will induce the mechanical resonance if the natural frequency is consistent with the excitation frequency, which is not allowed and must be avoided. Thus, the natural frequency of the pipeline system should be adjusted to avoid resonance.

\subsection{Modal Analysis}

A numerical simulation was used to calculate the mode of the multi-support pipeline system. The modal frequency results are shown in Table 3. 
Table 3 Frequency result of the multi-support pipeline system

\begin{tabular}{ll}
\hline Order & $\begin{array}{l}\text { Frequency } \\
\text { results } \\
(\mathbf{H z})\end{array}$ \\
\hline 1st & 216.4 \\
2nd & 345.6 \\
3rd & 393.9 \\
4th & 478.1 \\
5th & 534.6 \\
\hline
\end{tabular}

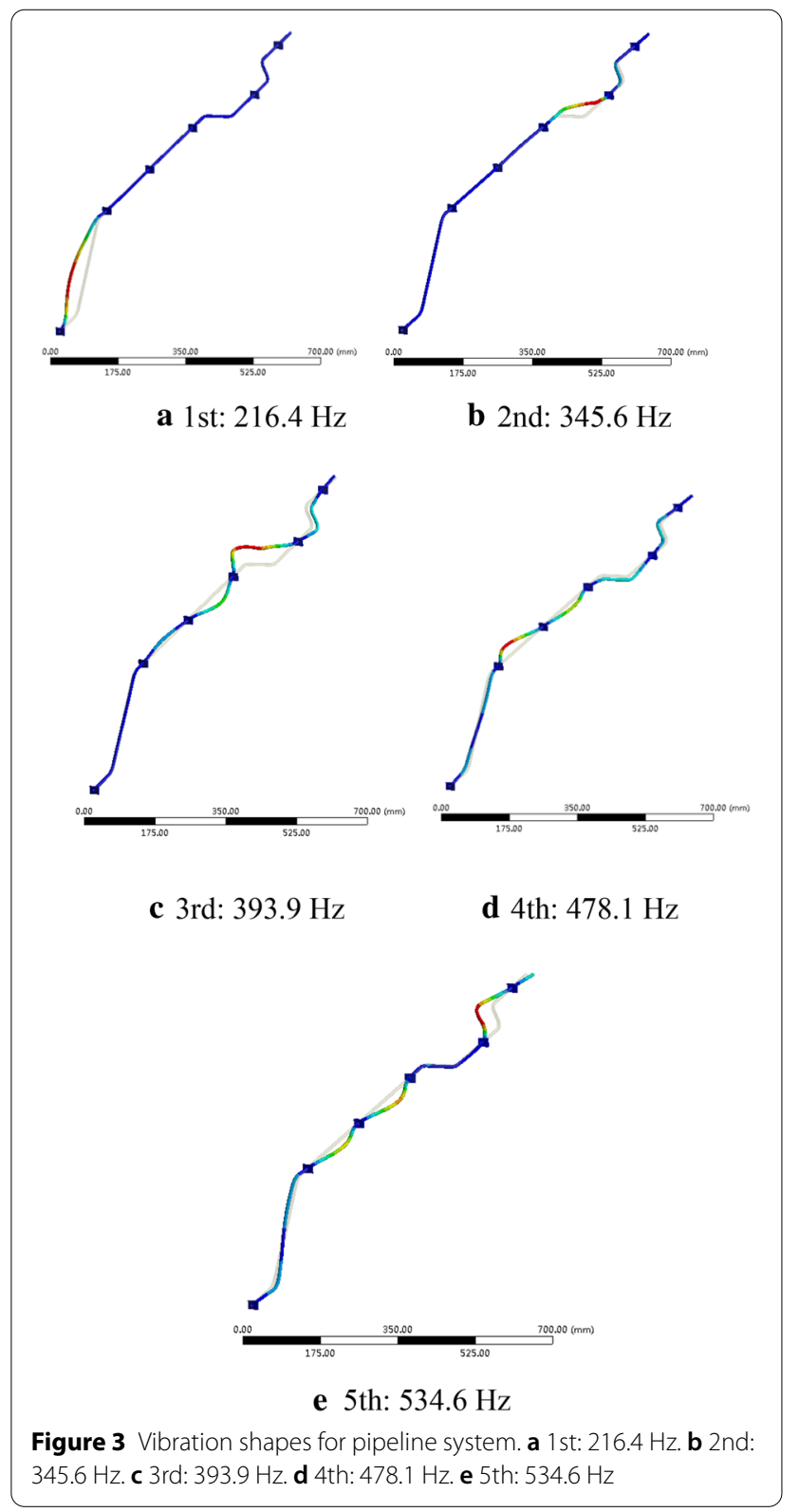

Vibration shapes are illustrated in Figure 3. It was found that the first-order natural frequency was approximately $216.4 \mathrm{~Hz}$, while the corresponding model shape exhibited horizontal vibration in the first span between support A and B; the second order was approximately $345.6 \mathrm{~Hz}$, and the large vibration amplitude at the fourth and fifth span of pipeline; the third order was approximately $393.9 \mathrm{~Hz}$, and bending vibration occurred at the fourth span of pipeline; the fourth order was approximately $478.1 \mathrm{~Hz}$, the model shape exhibited horizontal vibration, and large vibration amplitude occurred at the second span. The fifth order was approximately $534.6 \mathrm{~Hz}$, which indicated vibration in every span, while the occurrence of the largest amplitude occurred in the second span.

\subsection{Harmonic Analysis}

In order to study the steady-state response of the pipeline system when it is subjected to external excitation, it is necessary to perform a harmonic response analysis of the system, that is, to apply a load that varies with frequency.

ANSYS WorkBench was used to analyze the harmonic response of the multi-support pipeline system and calculated the stress response in the frequency range of 200-600 Hz. The constraint condition was that all clamps were constrained. Since the vibration is transmitted to the pipeline through clamps in the actual situation, a simple harmonic force excitation was applied to clamp $C$, and excitation force was $300 \mathrm{~N}$ along the $Z$ direction, the frequency sweep range was $200-600 \mathrm{~Hz}$, the step size was $1 \mathrm{~Hz}$.

The stress frequency response curve of multi-support pipeline system is illustrated in Figure 4. It can be seen that the response peaks were concentrated near the natural frequency. In the modal analysis, the structure had

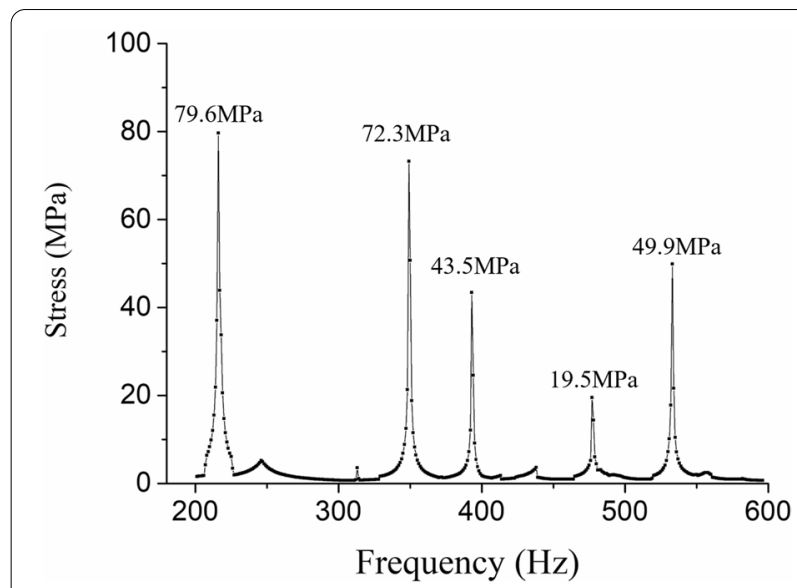

Figure 4 Stress frequency response curve of multi-support pipeline system 


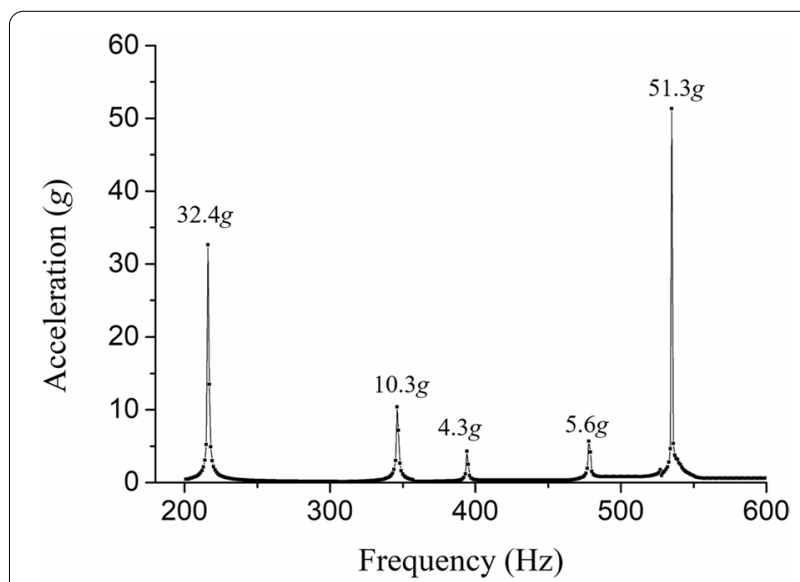

Figure 5 Acceleration frequency response curve of multi-support pipeline system

five natural frequencies within the frequency range of $200-600 \mathrm{~Hz}$, corresponding to 5 response peaks.

Figure 5 shows the acceleration frequency response curve of the multi-support pipeline system along with three directions. It can be seen that the peak value of the acceleration response was consistent with the frequency of the stress peak, and all of them were near the natural frequency. There were five acceleration peaks within the frequency range of $200-600 \mathrm{~Hz}$, the maximum response appears at $534.6 \mathrm{~Hz}$, and the amplitude is $51 g$.

\section{Clamp Position Optimization Based on Genetic Algorithm}

The hydraulic pipeline is the key structure to provide power transmission for the aircraft, and ensuring that the pipeline system does not cause resonance damage under external excitation is important to ensuring safety. In the design of hydraulic pipeline, the resonance problem is generally solved by adjusting the pipeline shape, increasing or reducing support constraints, and changing the position of clamps. However, for the pipeline system arranged in a narrow space like an aero-engine, it is difficult to change pipeline shape and increase support points, so the movement of the clamp position is used to achieve the aim of frequency adjustment.

\subsection{Optimization Setting}

\subsubsection{Multi-Objective Genetic Algorithm}

Compared with the traditional mathematical programming method, the multi-objective genetic algorithm has the following advantages [24-27].

1. It adopts efficient heuristic searching and starts operating based on a group rather than on the single point search. Searching involves the entire solution space and avoids falling into local optimal. GA also has a stronger global optimization ability.

2. GA has inherent parallelism, it can improve the running speed through calculation, and this method is more suitable for the optimization of large-scale complex problems.

To investigate the multi-support pipeline system, it was necessary to consider not only the complex combination of clamp positions and the variable range but also the adjustment of the natural frequency and the reduction of dynamic responses. Traditional optimization methods were difficult to apply because they required large-scale data calculation and global optimization. Therefore, the GA was used to search for the optimal results through successive generations.

\subsubsection{Optimization Targets}

For an aircraft hydraulic pipeline system, several objectives must be simultaneously satisfied to obtain an optimal solution. Occasionally, however, there was a conflict between these multiple objectives, which must be simultaneously satisfied [28]. In this part, two targets were defined.

(1) Adjustment of natural frequency

The natural frequency of the pipeline system changes at different clamp positions. According to the vibration design requirements for the structure, the clamps should be installed to keep the natural frequency away from the excitation frequency. Adjusting the natural frequency by changing the clamp position is advantageous in terms of the pipeline design avoiding resonance. Here, natural frequency $\omega_{i}$, where $\omega_{i}=\sqrt{k_{i} / m_{i}}$, was designed as the object of optimization, where $i$ denoted the order of the natural frequency.

(2) Minimum dynamic responses

Dynamic responses (stress and acceleration) are important in pipeline stability design. It is known that dynamic responses depend on the excitation frequency and mode. When the excitation is applied to a clamp, the change of clamp position will influence the pipeline's dynamic responses. The maximum dynamic stress $\sigma_{\max }$ and the maximum acceleration $a_{\max }$ were defined as optimization targets to be minimized.

\subsubsection{Constraint Condition}

(1) Clamp position constraint 


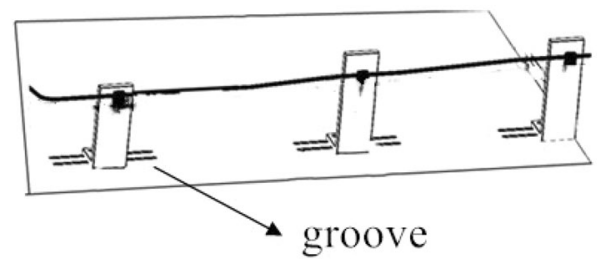

Figure 6 Schematic diagram of the movable clamp position and groove

Table 4 Range of available moving positions

\begin{tabular}{lcc}
\hline Parameter & Lower limit $(\mathbf{m m})$ & $\begin{array}{l}\text { Upper } \\
\text { limit } \\
(\mathbf{m m})\end{array}$ \\
\hline$D_{1}$ & 320 & 435 \\
$D_{2}$ & 600 & 770 \\
$D_{3}$ & 850 & 1010 \\
$D_{4}$ & 1200 & 1360 \\
$D_{5}$ & 1465 & 1600 \\
\hline
\end{tabular}

To simulate the limited clamp installation space and the adjustable clamp positions, the grooves were arranged along the direction of the clamp movement on the platform, as shown in Figure 6. The rib beams could move along the groove within a certain range, and the length of the groove was set according to the actual coordinates and movable ranges. According to the pipeline structure and support position, the groove's position was determined by the pipeline layout and the movable range of clamps.

The design of clamp positions is influenced by limited space. Thus, the range of available installation space should be considered in pipeline design. According to the above-mentioned modal and actual situation, the details of the available moving position are set as presented in Table 4.

(2) Natural frequency constraint

Moreover, we defined $\lambda=\omega / \omega_{n}$, where $\lambda$ was the frequency ratio, $\omega$ was the excitation frequency, and $\omega_{n}$ was the structure's natural frequency. The range of resonance could be considered as $0.8<\lambda<1.2$ [29]. Thus, we determined that the structure was at the risk of resonance when the natural frequencies in the range of $0.8 \omega<\omega_{n}<1.2 \omega$. To ensure that the frequencies were far away from the resonance frequency range, the frequency should agree with the following equation:

$$
P_{n}=\left(\omega_{n}-0.8 \underline{\omega}\right)\left(\omega_{n}-1.2 \bar{\omega}\right)>0,
$$

where $\underline{\omega}$ is the lower boundary, $\bar{\omega}$ is the upper boundary.

\subsubsection{Mathematical Optimization Model}

Optimization design is used to obtain the optimal solution in multiple schemes. Before optimization, a mathematical optimal model was established and mainly contained three basic elements: the objective function, design variables, and constraint conditions. In this study, the degree $Q_{n}$ used to determine the frequency far away from the working frequency range and the maximum dynamic stress response $\sigma_{\max }$ were considered as the optimization objective function. The position of support $D$ was considered as the optimization design variable, where $D=\left(D_{1}, D_{3}, D_{4}, D_{5}\right)^{\mathrm{T}}$. The initial sample value is set according to Table 1 . The complete mathematical optimization model of the pipeline system is established as follows:

$$
\left\{\begin{array}{l}
\max Q_{n} \\
\min \sigma_{\max } \\
\text { s.t.., } P_{n}=\left[\omega_{n}(D)-0.8 \underline{\omega}\right]\left[\omega_{n}(D)-1.2 \bar{\omega}\right]>0 \\
\sigma_{\max } \leq \sigma_{\max }^{0} \\
D=\left(D_{1}, D_{3}, D_{4}, D_{5}\right)^{\mathrm{T}} \\
\underline{D}_{i} \leq D_{i} \leq \bar{D}_{i} i=1,3,4,5
\end{array}\right.
$$

where $\omega_{n}(D)$ is the natural frequency under a certain support position, $\sigma_{\max }^{0}$ is the maximum stress of the pipeline system under the initial support position, $D_{i}$ is the design variety of the support position, $\underline{\underline{D}}_{i}$ is the lower value of the support moving range, and $\bar{D}_{i}$ is the upper value of the support moving range.

\subsection{Optimization Results and Analysis \\ 4.2.1 Optimization Design for Avoiding Aero-Engine Vibration Frequency}

The range of the aero-engine vibration frequency is close to $100-200 \mathrm{~Hz}$. According to the optimization objective, the natural frequency should be away from the working range of the engine by $20 \%$, that is, the frequency needs to be outside the range of $[80 \mathrm{~Hz}, 220 \mathrm{~Hz}]$. However, the initial clamp positions cannot satisfy the requirement. In the following work, we introduced an optimization design to calculation the best clamp position. Particularly, external excitation was applied to clamp $C$ when calculated the dynamic responses. The optimization results are presented in Table 5. 
Table 5 Calculation results before and after optimization

\begin{tabular}{llllllcc}
\hline Variable & $\boldsymbol{D}_{\mathbf{1}}(\mathbf{m m})$ & $\boldsymbol{D}_{\mathbf{3}}(\mathbf{m m})$ & $\boldsymbol{D}_{\mathbf{4}}(\mathbf{m m})$ & $\boldsymbol{D}_{\mathbf{5}}(\mathbf{m m})$ & $\begin{array}{l}\text { First-order } \\
\text { frequency }(\mathrm{Hz})\end{array}$ & $\begin{array}{l}\text { Maximum stress } \\
(\mathbf{M P a})\end{array}$ & $\begin{array}{l}\text { Maximum } \\
\text { acceleration } \\
(\boldsymbol{g})\end{array}$ \\
\hline Initial & 350 & 950 & 1250 & 1550 & 216 & 2.47 & 2.87 \\
Optimal & 322.97 & 891.58 & 1218.1 & 1503.8 & 248 & 1.91 & 1.70 \\
\hline
\end{tabular}

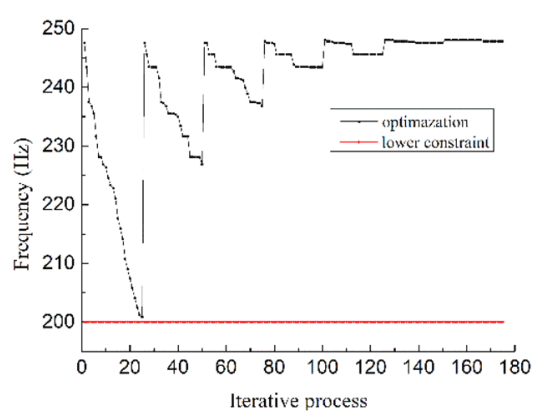

a Iterative process for first natural frequency

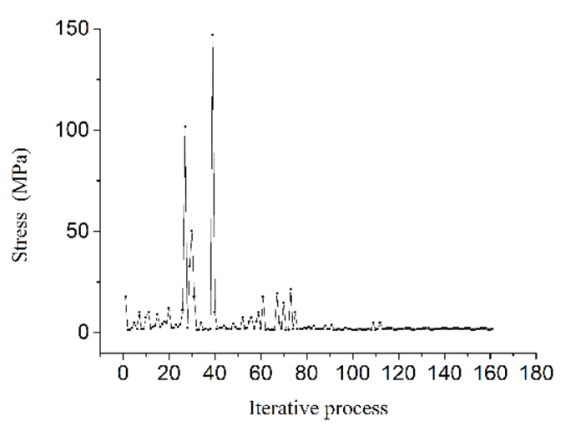

b Iterative process for maximum stress

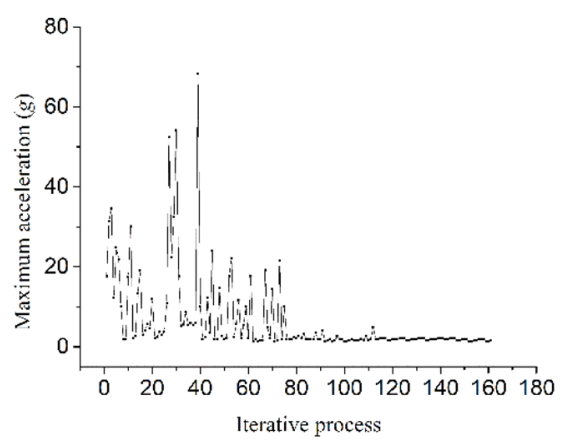

c Iterative process for maximum acceleration.

Figure $\mathbf{7}$ Iterative process for optimization calculation. a Iterative process for first natural frequency. $\mathbf{b}$ Iterative process for maximum stress. c lterative process for maximum acceleration

During the optimization process, using 50 samples as the initial optimization value. After 130 iterations of calculation, the results tend to be stable, as shown in Figure 7. The results show that the optimal first-order frequency was increased to $248 \mathrm{~Hz}$, which was $24 \%$ higher than the upper limit of the engine vibration frequency. The first model shape still maintained the horizontal resonance of the first span. The maximum response at the end of the first cross-pipeline was significantly reduced, with a reduction of more than $20 \%$.

When a parameter in the system changes, the system's state or responses may have a certain change. Sensitivity analysis is the method to study the influence of this parameter change on the sensitivity of the system response change [30]. Sensitivity analysis can also help to determine which parameters have a greater impact on the output responses and to provide guidance for structural performance optimization [31]. Therefore, sensitivity analysis has been widely used in many fields such as marketing, economic management, project proposal evaluation, and engineering optimization design. Sensitive analysis methods including the local sensitivity analysis method and the global sensitivity analysis method. The local sensitivity analysis method has a high computational efficiency when studying the influence of a single parameter change on the system. The global sensitivity analysis method is mainly used to investigate the complex nonlinear model. The influence of the interaction between parameters on the model can be analyzed to provide accurate and comprehensive analysis results through this method. In this part, we introduced the global sensitivity analysis method to study the relationship between the clamp positions and model responses.

Sensitivity analysis was used to investigate the changing relationship between the clamp positions and the first-order frequency, and the result is shown in Figure 8. We can clearly see that the parameter $D_{1}$ was the primary influence factor, and it displayed an inverse relationship with the first-order frequency. Briefly, the optimization results revealed that the objective of avoiding the engine's working range can be achieved by reducing parameter $D_{1}$.

\subsubsection{Optimization Design for Hydraulic Pump Vibration Frequency}

The working of aircraft hydraulic pumps can cause hydraulic piping system's vibration. When the pump's vibration frequency is close to the natural frequency of pipeline system, it will lead to the resonance of the 


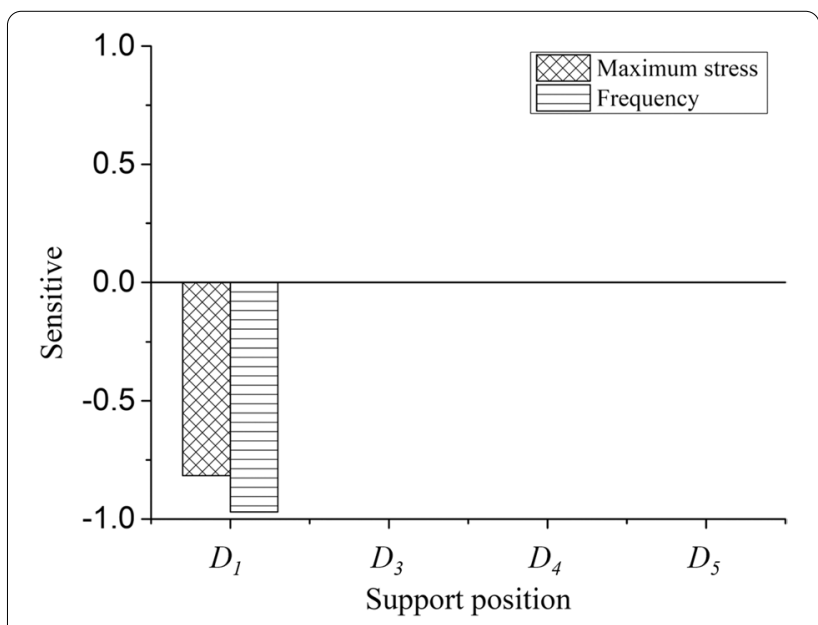

Figure $\mathbf{8}$ Result of sensitivity analysis of first-order natural frequency

pipeline system. The vibration frequency of hydraulic pump close to $400-580 \mathrm{~Hz}$. Through model analysis, it is found that this range contains the pipeline's fourth and fifth-order natural frequencies. And the third-order natural frequency of the structure is very close to $400 \mathrm{~Hz}$. In order to adjust the pipeline's natural frequency, genetic algorithms are applied to the optimization design. Table 6 shows the calculation results.

As can be seen in Table 6, the frequencies which closed to the pulsation range boundary were $355.1 \mathrm{~Hz}$ and $615.0 \mathrm{~Hz}$, and they also kept away from the pulsation range boundary by $11.2 \%$ and $2.5 \%$, respectively. The maximum stress that appeared at the end of the first pipeline span obviously decreased. The stress amplitude decreased by more than $60 \%$, compared with the initial stress value of $24.5 \mathrm{MPa}$. Additionally, the maximum acceleration exhibited a dramatic decrease, with $83.2 \%$. And Figure 9 shows the optimization process.

Figure 10 shows the sensitivity analysis results. In the optimization process, F1 and F2 represented the fourth and fifth-order frequencies, which approached the range boundary. According to the results, parameter $D_{4}$ did not have any influence. However, parameters $\mathrm{F} 1, D_{3}$, and $D_{5}$ exerted a dramatic influence on the optimal results. $D_{3}$ had an inverse relationship with the frequencies, and $D_{1}$ and $D_{5}$ had the opposite effect on the results. For parameter F2, parameters $D_{1}, D_{3}$, and $D_{5}$ influenced the result of F1, while $D_{1}$ and $D_{5}$ were positively correlated and $D_{3}$ had an inverse correlation with F2. Regarding maximum stress, only $D_{3}$ and $D_{5}$ influenced the maximum value, and the influence trend was similar to F1.

\section{Experimental Validation and Results Discussion \\ 5.1 Experimental Methods and Test devices}

(1) Mode experiment

In the mode experiment, the natural frequencies of the multi-support pipeline system were tested. The measuring direction was perpendicular to the rib beam. The ECON modal test system including a force hammer (PCB 086C03) and data collection and analysis instrument (ECON MI-7008) was used to test the target's mode. The operating principle of the mode test is shown in Figure 11.

The mode experiment was carried out by using the hammering method. In the mode test, single-point excitation and the multi-point response method were adopted. The force hammer knocked on the specimen's surface and acquired the response signal through acceleration sensors. We used the frequency response function (FRF) and modal parameter identification method to obtain the modal parameters. The FRF of each point was calculated through modal test software.

(2) Dynamic experiment

In the dynamic response experiment, the sinusoidal excitation generated by a vibration generator was applied to rib-beam support and induced the vibration of the pipeline system. The vibration generator is a device that exerts a certain predetermined vibration force on the measured object to produce vibration. Additionally, it can provide a stable excitation force within the required frequency range. The experiment was carried out through the EST100 vibration generator, and the data were acquired by the DEWEsoftX high-speed data acquisition system. The data acquisition system includes a high-speed data acquisition instrument, data analysis system, acceleration sensors ( $\mathrm{PCB} 352 \mathrm{C} 22$ ),

Table 6. Optimization results.

\begin{tabular}{|c|c|c|c|c|c|c|c|c|}
\hline Variety & $D_{1}(\mathrm{~mm})$ & $D_{3}(\mathrm{~mm})$ & $D_{4}(\mathrm{~mm})$ & $D_{5}(\mathrm{~mm})$ & $\begin{array}{l}\text { 4th order } \\
\text { frequency }(\mathrm{Hz})\end{array}$ & $\begin{array}{l}\text { 5th order } \\
\text { frequency }(\mathrm{Hz})\end{array}$ & $\begin{array}{l}\text { Maximum } \\
\text { stress (MPa) }\end{array}$ & $\begin{array}{l}\text { Maximum } \\
\text { acceleration } \\
(g)\end{array}$ \\
\hline Initial & 350.0 & 950.0 & 1250.0 & 1550.0 & 393.9 & 534.6 & 24.5 & 47.1 \\
\hline Optimal & 429.3 & 1004.2 & 1357.0 & 1543.0 & 355.1 & 615.0 & 8.6 & 7.91 \\
\hline
\end{tabular}




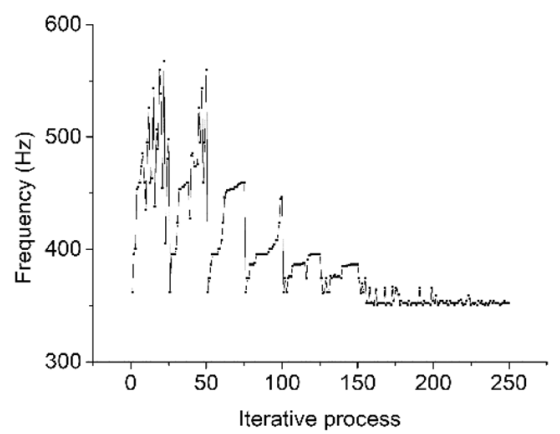

a Iterative process for forth order frequency

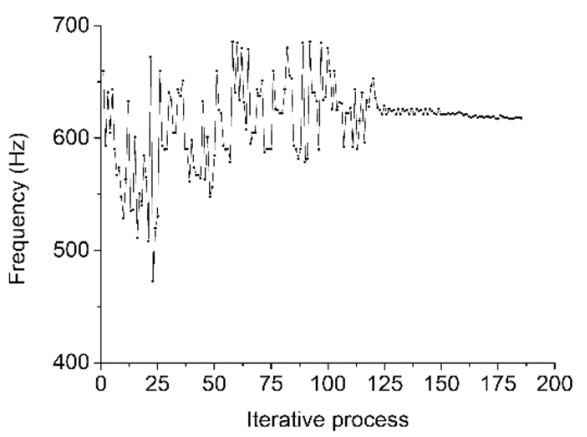

b Iterative process for fifth-order frequency

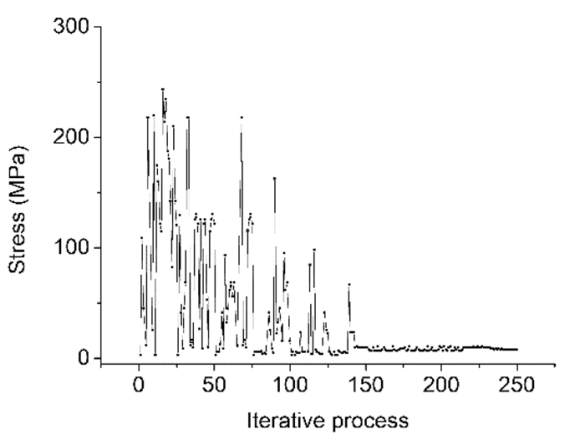

c Iterative process for maximum stress

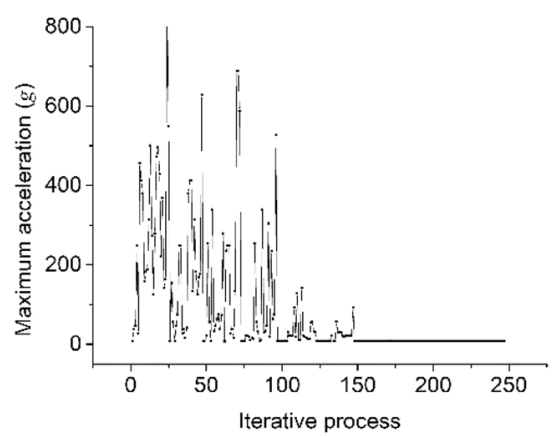

d Iterative process for maximum acceleration

Figure 9 Iterative process for optimization calculation. a Iterative process for forth order frequency. $\mathbf{b}$ Iterative process for fifth-order frequency. $\mathbf{c}$ Iterative process for maximum stress. $\mathbf{d}$ Iterative process for maximum acceleration

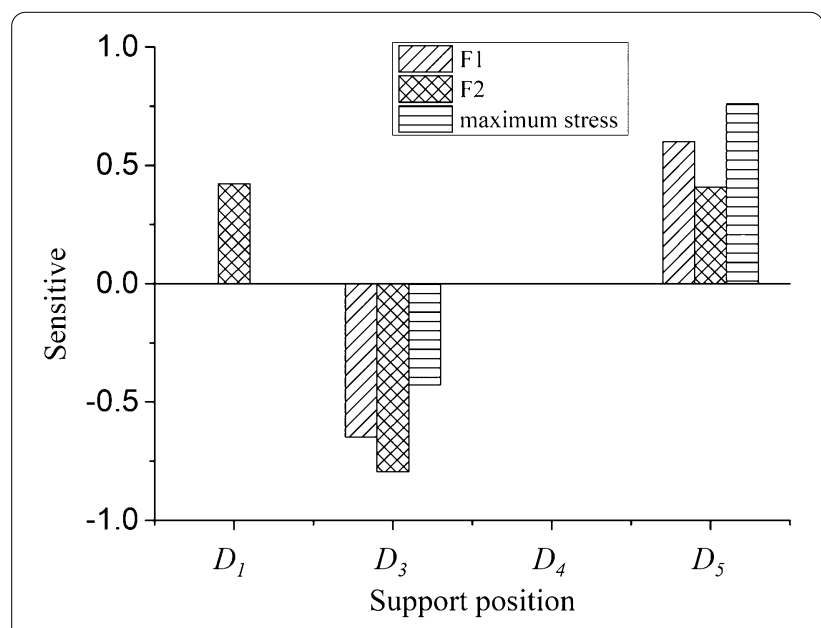

Figure 10 Sensitivity analysis of avoiding pump vibration frequency

and resistance strain gauges (BFH120-3AA-D150). Deformation and acceleration signals can be detected and the amplitudes can be displayed on the computer screen in real-time. The schematic diagram of the dynamic experiment is shown in Figure 12.

\subsection{Experimental Verification of Aero-Engine Vibration Frequency [80-220 Hz]}

\section{(1) Mode Results Verification}

This test was carried out to check whether the simulation result of the first natural frequency was away from the aero-engine working frequency. The test results are presented in Table 7. As can be seen, the test results agree with the simulation results. The maximum error was only $6.1 \%$, which can be accepted in engineering design. Because of the additional mass of the PCB acceleration sensors, the test frequency result was only slightly lower compared with the simulation results.

The mode results found that the first-order natural frequency of the optimized position reached $233 \mathrm{~Hz}$, which exceeds $20 \%$ of the upper limit of the engine vibration frequency, and the mode optimization results meet the needs.

At this time, it was necessary to apply the excitation to the pipeline to check the optimization effect and set the sweep frequency according to $120 \%$ of the working frequency band interval, that is, $[80-220 \mathrm{~Hz}]$. In the frequency sweep test, an obvious resonance occurred near $210 \mathrm{~Hz}$ at the initial position, and the acceleration and stress appeared maximum. When the clamp position was 


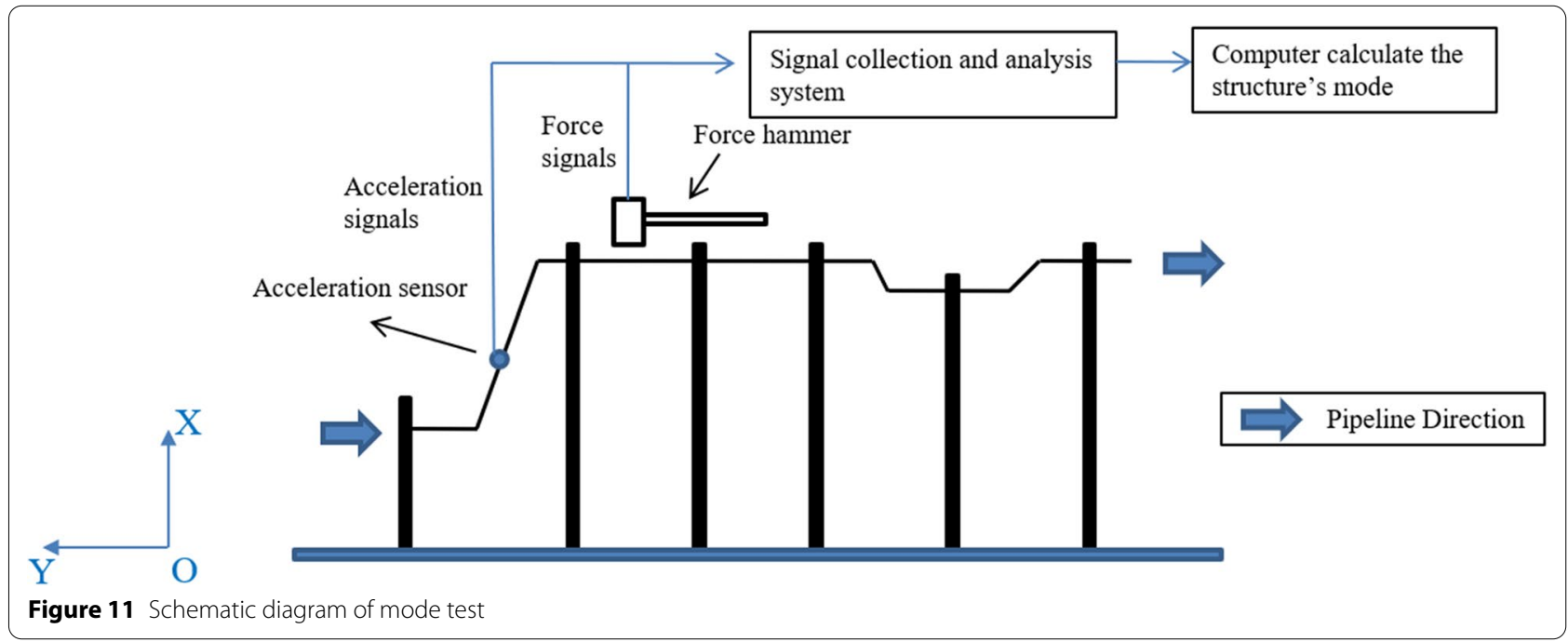

changed to the optimized position, there was no resonance phenomenon.

Figure 13 is a graph of dynamic response (stress and acceleration). It can be seen that when the clamp was readjusted in accordance with the results in Table 5 , the maximum dynamic stress and acceleration response decreased. As shown in Figure 13(a), at the initial position, the resonance of the pipeline occurred near $210 \mathrm{~Hz}$, and the dynamic stress appeared a peak at the same time, with a maximum value of $64.12 \mathrm{MPa}$. When the optimal clamp positions were used, the pipeline did not occur resonance during the frequency sweep, and the maximum stress response decreased to $4.11 \mathrm{MPa}$. In addition, as shown in Figure 13(b), the maximum acceleration at the initial position appeared in the A2 acceleration sensor, and the maximum acceleration was $51 g$. When the optimal clamp positions given in Table 6 were used, no acceleration peak appeared in the frequency sweeping process, and the maximum value of the entire result is $2.31 \mathrm{~g}$. Table 8 shows the value of maximum dynamic response and optimization effect during the tests.

In summary, based on the optimization of the clamp position, experimental research showed that the firstorder natural frequency of pipeline can be adjusted to more than $20 \%$ away from the vibration range of the engine. And in the case of the frequency sweep test, the optimized clamp positions made the dynamic responses significantly reduced. The optimized layout plan can provide a reference for engineering design.

\subsection{Experimental Verification of Pump Vibration Frequency [400-580 Hz]}

The vibration frequency range of hydraulic pump is 400-580 Hz. Experiments tested the pipeline's frequency under initial and optimal clamp positions, respectively. As can be seen from Figure 14, there were three different frequencies within the pump vibration frequency range, and MPF was the modal participation factor. After moving the clamp, the mode results showed that the third-order frequency decreased to $355.1 \mathrm{~Hz}$ and the fourth-order frequency increased to $615 \mathrm{~Hz}$. Pipeline's frequencies which close to pump vibration frequency have been adjusted, and the resonance risk caused by pump vibration can be eliminated.

Figure 15 shows the corresponding stress response and acceleration response in the case of frequency sweep. It can be seen that three peaks occurred in Figures 15(a) and (c). For the response of the optimized position (Figure 15(b)), stress amplitude greatly decreased, and only the acceleration response had an instantaneous peak value of $17 g$ (Figure 15(d)) in the frequency sweep process.

Figure 16 shows the value of dynamic response and comparison. Figure 16(a) shows the comparison of dynamic stress values under three different frequencies. It can be seen that the stress amplitude at the initial clamp position was relatively large, which was $4.85 \mathrm{MPa}(409.1 \mathrm{~Hz}$, S5), $13.03 \mathrm{MPa}(461.7 \mathrm{~Hz}, \mathrm{~S} 4)$, and $13.69 \mathrm{MPa}(533.6 \mathrm{~Hz}$, S2). After adjusting the clamp positions with the optimal result, the dynamic stress was significantly reduced, and the maximum stress was below $1.83 \mathrm{MPa}$. Compared with the initial maximum stress results, the amplitudes were significantly reduced by approximately $80.1 \%, 90.5 \%$, and $86.4 \%$, respectively. The maximum acceleration response also verified the optimal effect. Figure 16(b) shows that the maximum accelerations at three different frequencies were 24.56g (A5), 52.41 (A6), and 57.28g (A3), but the acceleration values were significantly reduced when the optimal 


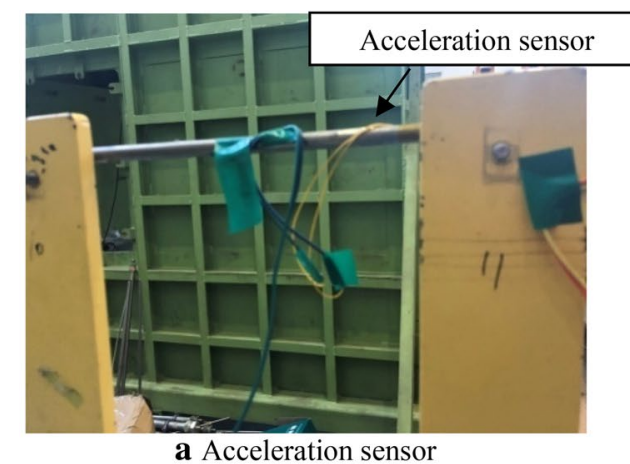

a Acceleration sensor

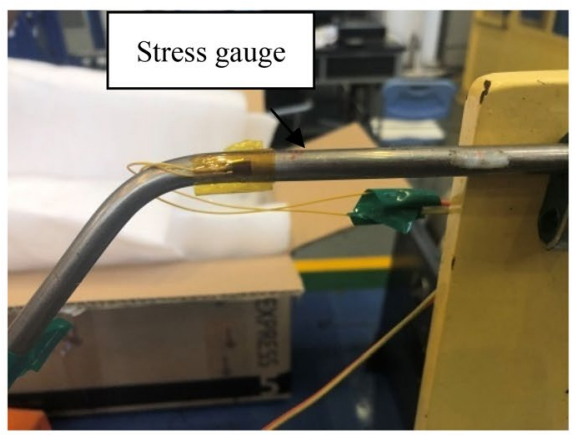

b Stress gauge

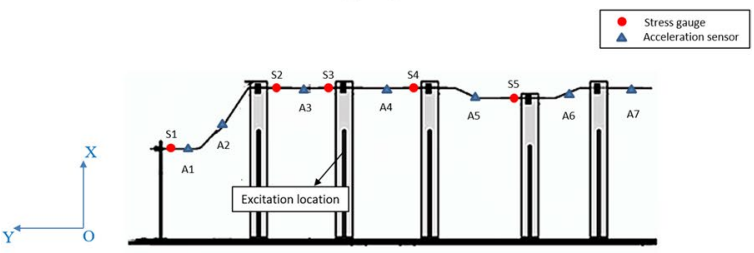

c Sensor installation position

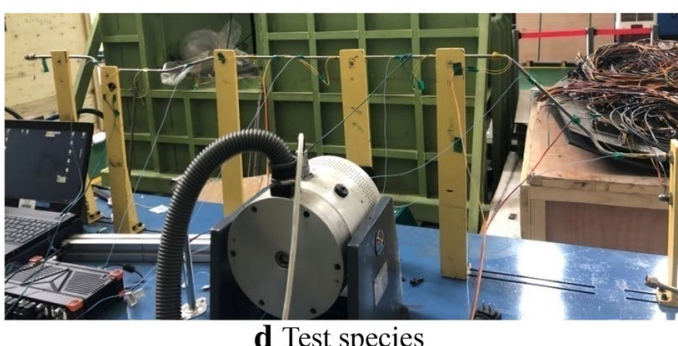

d Test species

Figure 12 Schematic diagram of dynamic experiment. a Acceleration sensor. b Stress gauge. c Sensor installation position. $\mathbf{d}$ Test species

Table 7 First-order frequency optimization effect verification

\begin{tabular}{llll}
\hline & $\begin{array}{l}\text { Simulation result } \\
(\mathbf{H z})\end{array}$ & Test result $\mathbf{( H z )}$ & Error (\%) \\
\hline Initial & 216 & $210 \mathrm{~Hz}$ & 2.9 \\
Optimal & 248 & $233 \mathrm{~Hz}$ & 6.1 \\
\hline
\end{tabular}

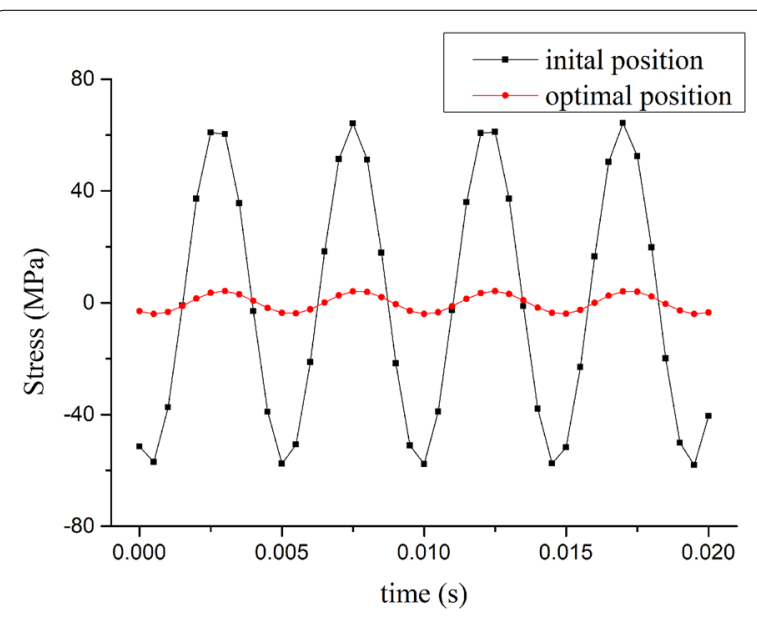

a Stress response under $210 \mathrm{~Hz}$

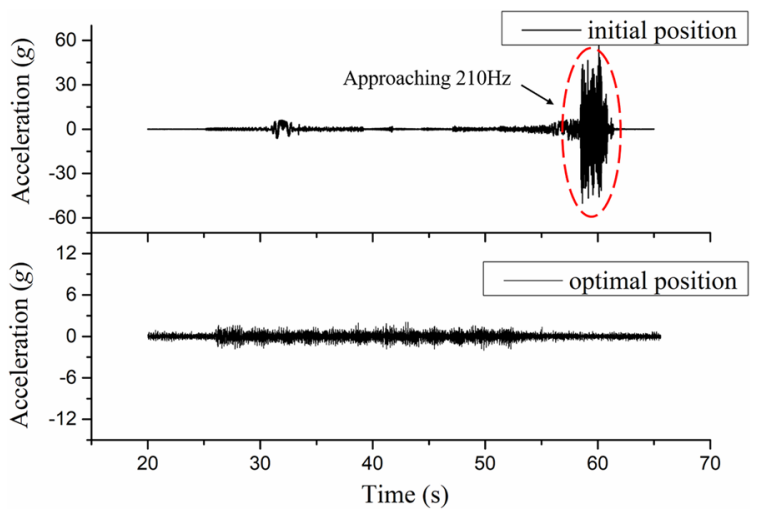

b Acceleration response of [80-220 Hz]

Figure 13 Dynamic test results and comparison. a Stress response under $210 \mathrm{~Hz}$. b Acceleration response of [80-220 Hz]

Table 8 Comparison of dynamic responses of $[80-220 \mathrm{~Hz}]$

\begin{tabular}{llll}
\hline Response characteristic & $\begin{array}{l}\text { Sensor (max } \\
\text { value) }\end{array}$ & \multicolumn{2}{l}{ Value } \\
\cline { 3 - 4 } & & Initial & Optimal \\
\hline Maximum stress (MPa) & S1 & 64.12 & 4.11 \\
Maximum acceleration $(g)$ & A2 & 51 & 2.31 \\
\hline
\end{tabular}

position was used. In addition, by comparing the initial and optimal results, we determined that the maximum drop was approximately $91.3 \%$ at $409.1 \mathrm{~Hz}$.

From the above discussion, the optimized design method proposed in this paper can effectively adjust the natural frequency of the pipeline, reduce the dynamic response of the pipeline, and avoid failure of the pipeline system caused by 

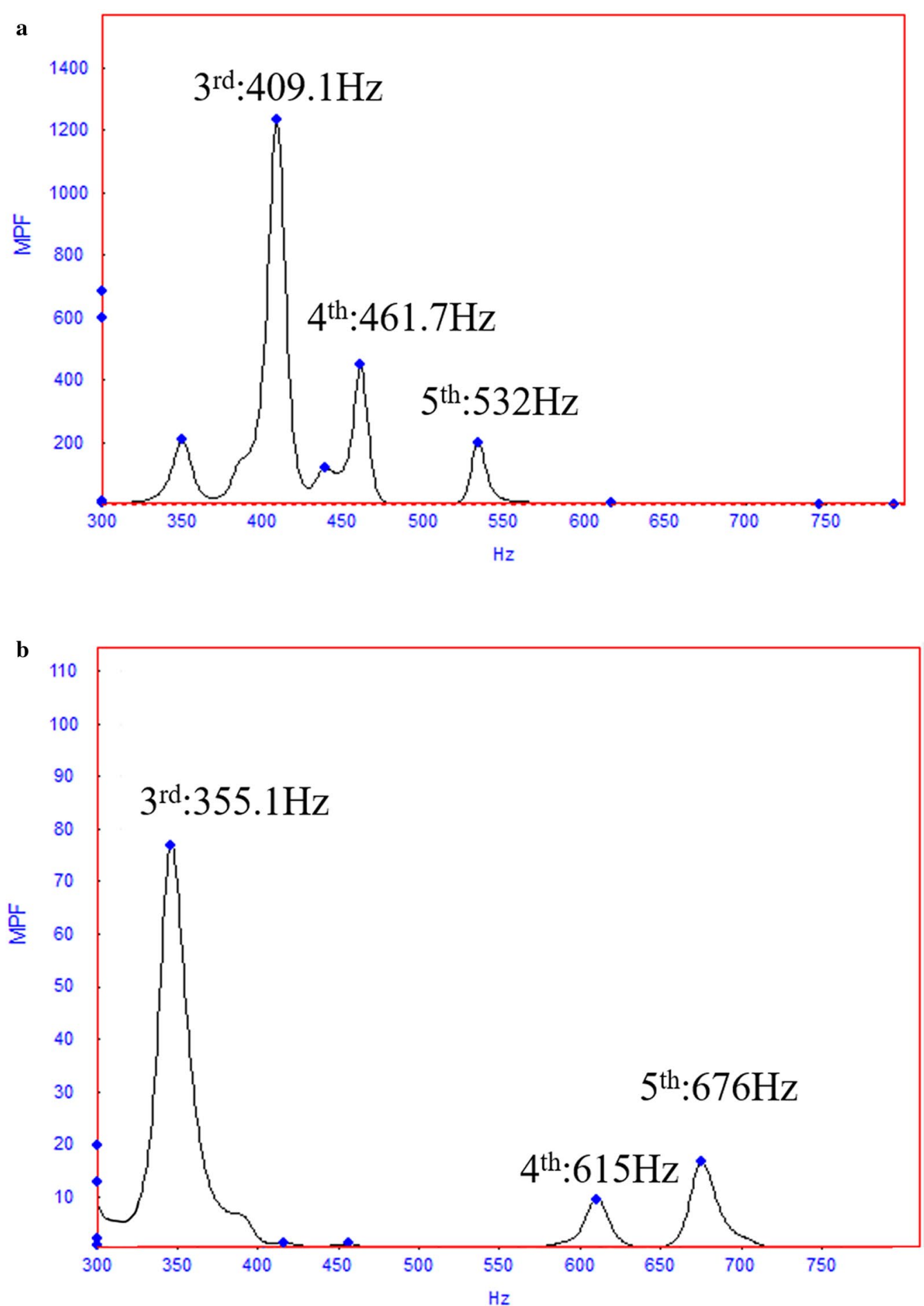

Figure 14 Mode participation before and after optimization. a Initial position. b Optimal position

resonance. The method was verified through corresponding experiments, and its optimization effect meets actual needs, which has certain guiding significance for practical engineering design.

\section{Conclusions}

In this paper, a multi-support pipe system with parameterized clamp position was established. Then, the genetic algorithm was used to calculate the calculation results. 


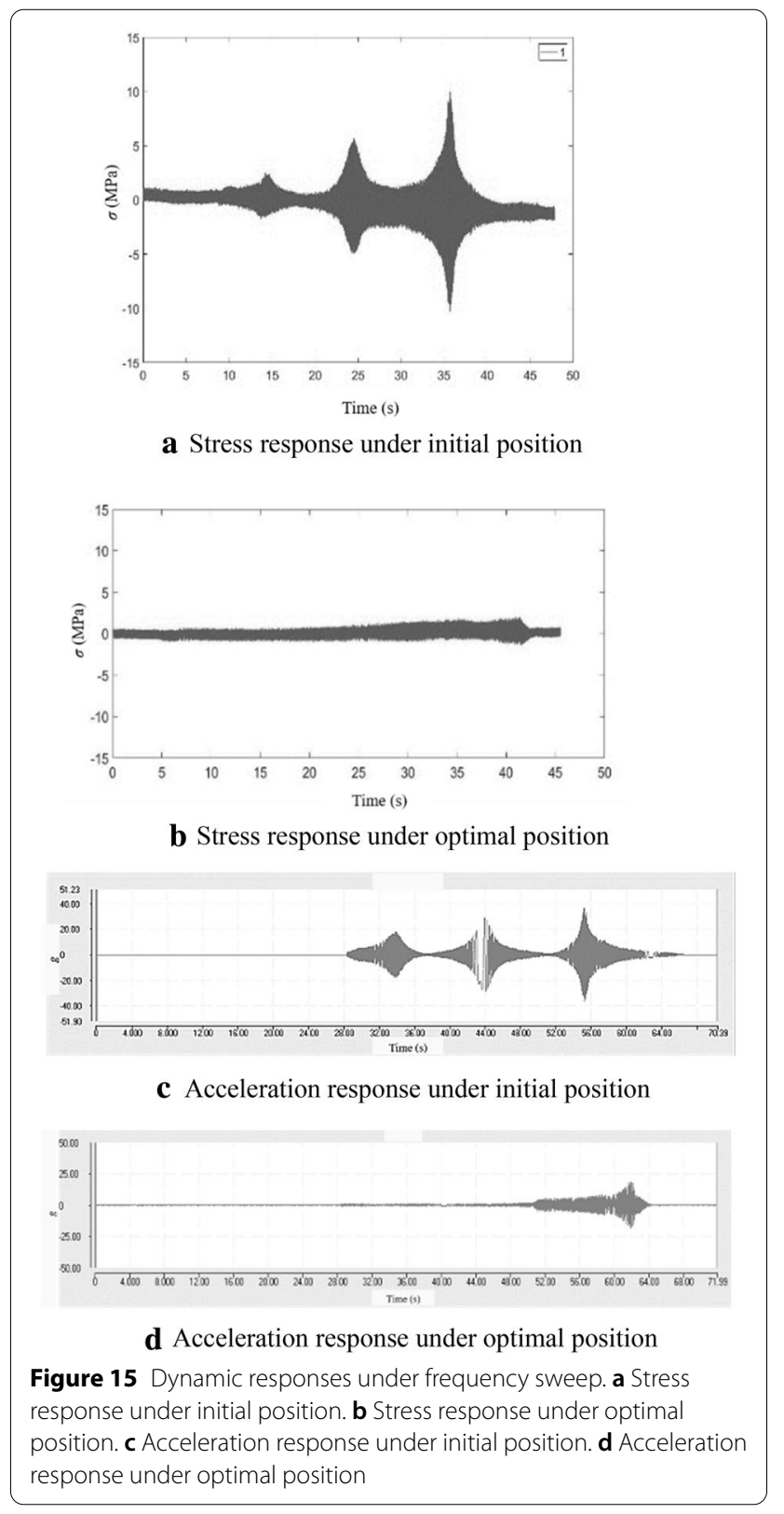

The optimal results obtained after more than 250 iterations solved the problems of frequency adjustment and dynamic response reduction. The actual optimization effect was verified through relevant experiments, and the results showed that the optimization effect met the engineering requirements. From the optimization process and experimental verification results, the following conclusions can be drawn.

- Optimized design based on the genetic algorithm can help find the optimal clamp position in a multi-support pipeline system with limited installation space.

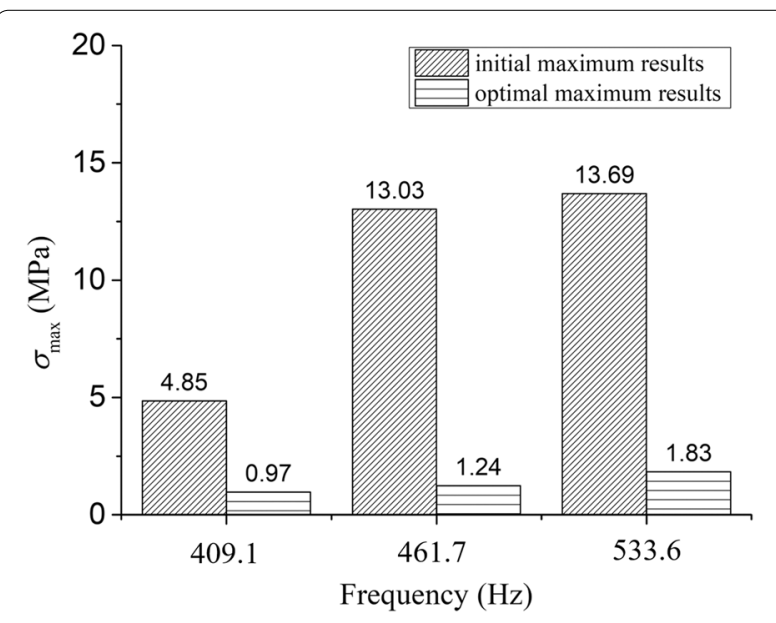

a Maximum stress value and comparison under three frequencies

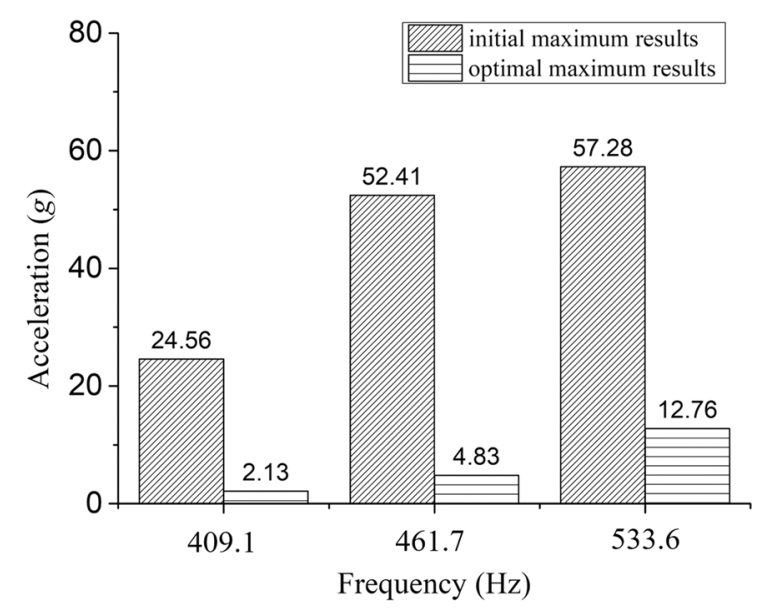

b Maximum acceleration value and comparison under three frequencies

Figure 16 Comparison of optimization results. a Maximum stress value and comparison under three frequencies. b Maximum acceleration value and comparison under three frequencies

- Through the sensitivity analysis, the relationship between the natural frequency and the clamp positions can be obtained. The results showed that: (1) Pipeline's first-order frequency will show a significant decrease when the distance between the first and second clamps increase. (2) The natural frequencies (3rd and 4th order) and the dynamic responses will show a significant decrease when the distance between the first and fourth clamps increase. (3) The natural frequencies (3rd and 4th order) and the dynamic responses will show a sig- 
nificant increase when the increase of the distance between the first and last clamps. The sensitivity analysis results can be a guide to the pipeline system design.

- By optimizing the design of avoiding the vibration frequency of the engine, it was determined that the first-order natural frequency of the pipeline was significantly increased and kept away from the engine vibration range, and the amplitude was greater than $20 \%$. In addition, the test results showed that after optimizing the clamp position, the dynamic response was significantly reduced compared to the original position.

- By optimizing the design of the pump vibration frequency, the optimization results revealed that the natural frequency of the pipeline system kept away from the pump vibration frequency range. In addition, the test results showed that the maximum stress and acceleration were significantly reduced by more than $80.1 \%$.

\begin{abstract}
Authors' information
Xiantao Zhang, born in 1995, is currently a PhD candidate at School of Mechanics, Civil Engineering and Architecture, Northwestern Polytechnical University, China. He received his master's degree from Northwestern Polytechnical University, China, in 2020. His research interests include structural design and fault diagnosis of aeroengine. Tel: +86-18992590111; E-mail: zhangxiantao@ mail.nwpu.edu.cn.

Wei Liu, born in 1981, is currently associate professor at School of Mechanics, Civil Engineering and Architecture, Northwestern Polytechnical University, China. His research interests include the dynamic design of aircraft pipeline system. E-mail: liuwei@nwpu.edu.cn.

Yamei Zhang, born in 1996, is currently a master candidate at School of Mechanics, Civil Engineering and Architecture, Northwestern Polytechnical University, China.

Yujie Zhao, born in 1995, is currently a master candidate at School of Mechanics, Civil Engineering and Architecture, Northwestern Polytechnical University, China.
\end{abstract}

\section{Acknowledgements}

The authors also thank Northwestern Polytechnical University's Key Laboratory of Aircraft Structure Integrity for providing relevant experimental equipment.

\section{Authors' contributions}

XZ was a major contributor in writing the manuscript and in the interpretation of the result. WL provided guidance and modified the manuscript. YMZ and YJZ were involved in the experiment and the data collection process. All authors read and approved the final manuscript.

\section{Funding}

Supported by National Natural Science Foundation of China (Grant No. 51875460), Aviation Power Foundation (Grant No. 6141B090320), and Foundation of Innovation and Creation for Graduate Students in Northwestern Ploytechnical University (Grant No. ZZ2019124). All funding bodies did not influence the study at any stage.

\section{Competing interests}

The authors declare that they have no competing interests.

Received: 11 January 2020 Revised: 10 December 2020 Accepted: 15 December 2020

Published online: 09 January 2021

\section{References}

[1] X Li, S Wang. Flow field and pressure loss analysis of junction and its structure optimization of aircraft hydraulic pipe system. Chinese Journal of Aeronautics, 2013, 26(4): 1080-1092.

[2] G Liu, Y Li. Vibration analysis of liquid-filled pipelines with elastic constraints. Journal of Sound \& Vibration, 2011, 330(13): 3166-3181.

[3] S A Bezborodov, A M Ulanov. Calculation of vibration of pipeline bundle with damping support made of MR material. Procedia Engineering, 2017, 176: 169-174.

[4] A E Mamaghani, S E Khadem. Vibration control of a pipe conveying fluid under external periodic excitation using a nonlinear energy sink. Nonlinear Dynamics, 2016, 86(3): 1761-1795.

[5] Q Chai, J Zeng, $\mathrm{H} \mathrm{Ma}$, et al. A dynamic modeling approach for nonlinear vibration analysis of the L-type pipeline system with clamps. Chinese Journal of Aeronautics, 2020. https://doi.org/10.1016/j.cja.2020.04.007.

[6] PX Gao, JY Zhai, Y Y Yan, et al. A model reduction approach for the vibration analysis of hydraulic pipeline system in aircraft. Aerospace Science and Technology, 2016, 49: 144-153.

[7] PX Gao, JY Zhai, F Z Qu, et al. Vibration and damping analysis of aerospace pipeline conveying fluid with constrained layer damping treatment. Journal of Aerospace Engineering, 2018, 232(8): 1529-1541.

[8] PX Gao, JY Zhai, Q K Han, et al. Dynamic response analysis of aero hydraulic pipeline system under pump fluid pressure fluctuation. Journal of Aerospace Engineering, 2019, 233(5): 1585-1595.

[9] Y J Lv, G Zhao. UG-based research and development of 3D pipe layout system of the aircraft engine. Procedia Engineering, 2011, 17: 660-667.

[10] S Pourzeynali, M Zarif. Multi-objective optimization of seismically isolated high-rise building structures using genetic algorithms. Journal of Sound \& Vibration, 2008, 311(3-5): 1141-1160.

[11] A H M Kwong, K A Edge. A method to reduce noise in hydraulic systems by optimizing pipe clamp locations. Proceedings of the Institution of Mechanical Engineers, Part l: Journal of Systems and Control Engineering, 1998, 212(4): 267-280.

[12] A Asmara, U Nienhuis. Automatic pipeline system in ship. International Conference on Computer and IT Application, 2006 May 8-10, Delft, Netherlands, 2006: 269-280.

[13] CY Lee. An algorithm for path connections and its applications. IRE Transactions on Electronic Computers, 1961, 10(3): 346-365.

[14] Liu Q, Li M. Multi-objective layout optimization for branch pipe of aeroengine based on MOPSO. Journal of Mechanical Engineering, 2018, 54(19): 197-203. (in Chinese)

[15] T Ito. A genetic algorithm approach to piping route path planning. Journal of Intelligent Manufacturing, 1999, 10(1): 103-114.

[16] T Ren, Z L Zhu, G M Dimirovski. A new pipe routing method for aeroengines based on genetic algorithm. Proceedings of the Institution of Mechanical Engineers, Part G: Journal of Aerospace Engineering, 2014, 228(3): 424-434

[17] K Chen, W Q Shen. Further experimental study on the failure of fully clamped steel pipes. International Journal of Impact Engineering, 1998, 21(3): 177-202.

[18] X Li, X P Wang. Vibration control analysis for hydraulic pipelines in an aircraft based on optimized clamp layout. Journal of Vibration and Shock, 2013, 32(1):14-20. (in Chinese)

[19] A Li, Q Lan, D Dong, et al. Integrated design and process analysis of a blow molding turbo-charged pipe. The International Journal of Advanced Manufacturing Technology, 2014, 73(1-4): 63-72.

[20] W Liu, Y S Liu, Z Z Gao, et al. Random vibration analysis of pipelines system under external field excitation. Machinery Design \& Manufacture, 2010, 12(6): 814-818. (in Chinese) 
[21] WY Jiang, Y Lin, M Chen, et al. A co-evolutionary improved multi-ant colony optimization for ship multiple and branch pipe route design. Ocean Engineering, 2015, 102: 63-70.

[22] Y Qu, D Jiang, Q Yang. Branch pipe routing based on 3D connection graph and concurrent ant colony optimization algorithm. Journal of Intelligent Manufacturing, 2018, 29: 1647-1657.

[23] P X Gao. Vibration analysis of aero hydraulic pipeline system under multiexcitations and its constrained layer damping technology. Dalian: Dalian University of Technology, 2017. (in Chinese)

[24] Q Zhang, Y Mao, H Zhou, et al. Vibro-acoustics of a pipeline centrifugal compressor Part II. Control with the micro-perforated panel. Applied Acoustics, 2018, 132: 152-166.

[25] M Langwieser. Selection of objective functions and application of genetic algorithms in damping design of pipe system. Acta Mechanica Solida Sinca, 2003, 16(2): 171-178.
[26] D E Goldberg. Genetic algorithms in search, optimization, and machine learning. Boston: Addison-Wesley Longman Press, 1989.

[27] M Gen, R Cheng. Genetic algorithms and engineering optimization. New York: Wiley Press, 2000.

[28] C A Coello, A D Christiansen. Multiobjective optimization of trusses using genetic algorithms. Computers \& Structures, 2000, 75(6): 647-660.

[29] Y M Zhang. Mechanical vibration. Beijing:Tsinghua University Press, 2012. (in Chinese)

[30] X K Feng, Z Z Lyu, X Jiang. Efficient algorithm for estimating derivativebased global sensitivity index. Acta Aeronautica et Astronautica Sinica, 2018, 39(3): 22169. (in Chinese)

[31] S Liu, J Dai, A Li, et al. Analysis of frequency characteristics and sensitivity of compliant mechanisms. Chinese Journal of Mechanical Engineering, 2016, 29(4): 1-14

\section{Submit your manuscript to a SpringerOpen ${ }^{\odot}$ journal and benefit from:}

- Convenient online submission

- Rigorous peer review

- Open access: articles freely available online

- High visibility within the field

- Retaining the copyright to your article

Submit your next manuscript at $\boldsymbol{\nabla}$ springeropen.com 